\title{
Effectiveness of isolation policies in schools: Evidence from a mathematical model of influenza and COVID-19
}

\author{
Adam AC Burns ${ }^{1}$, Alexander Gutfraind ${ }^{\text {Corresp. 1, } 2}$ \\ 1 Division of Hepatology, Department of Medicine, Loyola University of Chicago, Maywood, IL, United States of America \\ 2 Division of Epidemiology and Biostatistics, School of Public Health, University of Illinois at Chicago, Chicago, IL, United States of America \\ Corresponding Author: Alexander Gutfraind \\ Email address: agutfrai@uic.edu
}

Background: Non-pharmaceutical interventions such as social distancing, school closures and travel restrictions are often implemented to control outbreaks of infectious diseases. For influenza in schools, the Center of Disease Control (CDC) recommends that febrile students remain isolated at home until they have been fever-free for at least one day and a related policy is recommended for SARS-CoV2 (COVID-19). Other authors proposed using a school week of four or fewer days of in-person instruction for all students to reduce transmission. However, there is limited evidence supporting the effectiveness of these interventions.

Methods: We introduced a mathematical model of school outbreaks that considers both intervention methods. Our model accounts for the school structure and schedule, as well as the time-progression of fever symptoms and viral shedding. The model was validated on outbreaks of seasonal and pandemic influenza and COVID-19 in schools. It was then used to estimate the outbreak curves and the proportion of the population infected (attack rate) under the proposed interventions.

Results: For influenza, the CDC-recommended one day of post-fever isolation can reduce the attack rate by a median (interquartile range) of $29(13-59) \%$. With two days of post-fever isolation the attack rate could be reduced by $70(55-85) \%$. Alternatively, shortening the school week to four and three days reduces the attack rate by $73(64-88) \%$ and $93(91-97) \%$, respectively. For COVID-19, application of post-fever isolation policy was found to be less effective and reduced the attack rate by $10(5-17) \%$ for a two-day isolation policy and by $14(5-26) \%$ for 14 days. A four-day school week would reduce the median attack rate in a COVID-19 outbreak by $57(52-64) \%$, while a three-day school week would reduce it by $81(79-83) \%$. In both infections, shortening the school week significantly reduced the duration of outbreaks.

Conclusions: Shortening the school week could be an important tool for controlling influenza and COVID-19 in schools and similar settings. Additionally, the CDC-recommended post-fever isolation policy for influenza could be enhanced by requiring two days of isolation instead of one. 


\section{Effectiveness of Isolation Policies in Schools: Evidence from a}

\section{Mathematical Model of Influenza and COVID-19}

3

4

5

$6{ }^{1}$ Division of Hepatology, Department of Medicine, Loyola University Medical Center,

7 Maywood, IL, USA

$8{ }^{2}$ Division of Epidemiology and Biostatistics, School of Public Health, University of Illinois at

9 Chicago, Chicago, IL, USA

10

11 CORRESPONDING AUTHOR:

12 Alexander Gutfraind, Ph.D.

13 School of Public Health

14 University of Illinois at Chicago

151603 W. Taylor Street, Chicago, IL 60612, U.S.A.

16 agutfrai@uic.edu 607-379-1361
Adam A. C. Burns ${ }^{1}$, Alexander Gutfraind ${ }^{1,2}$ 


\section{Abstract}

20 Background: Non-pharmaceutical interventions such as social distancing, school closures and

21 travel restrictions are often implemented to control outbreaks of infectious diseases. For

22 influenza in schools, the Center of Disease Control (CDC) recommends that febrile students

23 remain isolated at home until they have been fever-free for at least one day and a related policy is

24 recommended for SARS-CoV-2 (COVID-19). Other authors proposed using a school week of

25 four or fewer days of in-person instruction for all students to reduce transmission. However,

26 there is limited evidence supporting the effectiveness of these interventions.

27 Methods: We introduced a mathematical model of school outbreaks that considers both

28 intervention methods. Our model accounts for the school structure and schedule, as well as the

29 time-progression of fever symptoms and viral shedding. The model was validated on outbreaks

30 of seasonal and pandemic influenza and COVID-19 in schools. It was then used to estimate the

31 outbreak curves and the proportion of the population infected (attack rate) under the proposed

32 interventions.

33 Results: For influenza, the CDC-recommended one day of post-fever isolation can reduce the

34 attack rate by a median (interquartile range) of 29 (13 - 59)\%. With two days of post-fever

35 isolation the attack rate could be reduced by $70(55-85) \%$. Alternatively, shortening the school

36 week to four and three days reduces the attack rate by $73(64-88) \%$ and $93(91-97) \%$,

37 respectively. For COVID-19, application of post-fever isolation policy was found to be less

38 effective and reduced the attack rate by $10(5-17) \%$ for a two-day isolation policy and by $14(5$ -

39 26)\% for 14 days. A four-day school week would reduce the median attack rate in a COVID-19 
40 outbreak by $57(52-64) \%$, while a three-day school week would reduce it by $81(79-83) \%$. In

41 both infections, shortening the school week significantly reduced the duration of outbreaks.

42 Conclusions: Shortening the school week could be an important tool for controlling influenza

43 and COVID-19 in schools and similar settings. Additionally, the CDC-recommended post-fever

44 isolation policy for influenza could be enhanced by requiring two days of isolation instead of

45 one. 
49

50

51

52

54

55

\section{Introduction}

Respiratory infections are the leading cause of death in low- or middle-income countries and account for an estimated four million deaths annually(Mathers \& World Health Organization, 2008). For rapidly emerging outbreaks such as novel strains of influenza or SARS-CoV-2, pharmaceutical measures may be unavailable or ineffective, in which case non-pharmaceutical intervention measures (NPIs) may be the first line of response against infection(Ferguson et al., 2006; Cowling et al., 2020). However, there is currently an acute need to develop and validate NPIs for COVID-19 (the disease caused by the SARS-CoV-2 virus)(Brauner et al., 2020) and refine the understanding of NPIs for controlling influenza("WHO | Non-pharmaceutical public health measures for mitigating the risk and impact of epidemic and pandemic influenza," 2019).

Our study directly addresses this need by using a computational model to examine the impact of several NPIs, focusing on a shortened school week and symptom-based isolation policies. The shortened school week policy involves closure of the school for additional days to extend the weekend (e.g. closure every Thursday and Friday)(Faherty et al., 2019; Karin et al., 2020), thus creating a period of additional physical isolation between the students, and possibly conducting at-home learning on those days. The symptom-based isolation policy involves isolating individuals at the onset and for the duration of fever symptoms, normally followed by additional days of isolation. Additionally we considered increasing compliance and monitoring, reducing cross-grade contact, and complete weekend quarantine policies.

For controlling pandemic and seasonal influenza outbreaks, the symptom-based NPI with one day of post-fever isolation is currently recommended by the US Centers of Disease Control and Prevention (CDC)(Centers for Disease Control and Prevention, 2018),(Qualls et al., 2017), and is referred to as fever absenteeism or a return-to-school policy(Miller et al., 2013). The buffer 
72 period of one day reduces transmission from infectious students in situations where their fever

73 symptoms temporarily subside or when they continue shedding the virus at the end of the course

74 of illness(Carrat et al., 2008).

75 For COVID-19 outbreaks, there are currently divergent recommendations from public health 76 authorities, and there have been several changes in guidelines. For symptomatic patients, the

77 WHO currently recommends 10 days of isolation after symptom onset, plus at least 3 additional

78 days without symptoms, while for asymptomatic patients it recommends 10 days after positive

79 test for SARS-CoV-2(WHO). The CDC recommends that patients with COVID-19 symptoms

80 isolate until they have met all three conditions: (1) they have been fever-free for 24 hours

81 without the use of fever-reducing medications, (2) it has been 10 days since the onset of their

82 symptoms and (3) their COVID-19 symptoms have been improving(Centers for Disease Control

83 and Prevention, 2020). Finally, the Swedish Public Health Agency (SPHA), which previously

84 required two days free of symptoms, currently gives the schools control in establishing their own

85 isolation policies("Information till förskola, grundskola och gymnasier om covid-19 -

86 Folkhälsomyndigheten”).

87 To evaluate the various NPIs, our model computationally simulates outbreaks of influenza and 88 COVID-19 in school settings, and then looks at the effect of isolation policies on the attack rate

89 (i.e. the proportion of the student population infected over the duration of the outbreak) and the

90 outbreak curve (i.e. prevalence of infected students at each day of the outbreak). Our work builds

91 upon previous studies that have applied mathematical models to school-based influenza

92 transmission(Halloran et al., 2008; Coburn, Wagner \& Blower, 2009; Chao et al., 2010;

93 Christensen et al., 2010). The policy of symptom monitoring, which isolates contacts after onset

94 of symptoms, has been examined computationally and shown to be sufficient for controlling 
95 certain outbreaks(Peak et al., 2017). Several studies also modeled non-pharmaceutical

96 interventions such as closures but not absenteeism policies(Andreasen \& Frommelt, 2005; Milne

97 et al., 2008; Cauchemez et al., 2009; Sasaki et al., 2009; Rhodes \& Hollingsworth, 2009; Bansal

98 et al., 2010; Lee et al., 2010; Christensen et al., 2010; Stebbins et al., 2011; Araz et al., 2012;

99 Jackson et al., 2013; Diedrichs, Isihara \& Buursma, 2014; Eames, 2014). We retrieved all studies

100 that evaluated isolation policies by using a broad search on PubMed and found that many

101 modeling studies assumed isolation for a fixed interval following diagnosis but not in a symptom-

102 dependent way(Halloran et al., 2008). We also found several comprehensive computational

103 studies of school closures and isolation of infected students(Halloran et al., 2008; Kelso, Milne \&

104 Kelly, 2009), but did not find evaluation of symptom-based isolation policies. The policy of

105 shortening school weeks was recently examined in a modeling study(Karin et al., 2020) that

106 found that closures for ten days followed by four days of schooling could be effective in

107 controlling COVID-19, but our model is the first to examine the modification of a standard five108 day school schedule.

109

110 Despite the promise of post-fever isolation for both COVID-19 and influenza, we hypothesized

111 at the outset of this project that the policy would merely have a small effect in controlling

112 outbreaks. We speculated that the CDC-recommended single day of post-fever isolation might

113 not be enough to achieve a meaningful reduction in influenza transmission. Furthermore,

114 parental non-compliance may make the policy ineffective. As compared to influenza, the policy

115 would be less effective in COVID-19 outbreaks since children have a higher rate of

116 asymptomatic infections(Poletti et al., 2020). On the other hand, if the policy were proven

117 effective for either outbreak, it is not known whether one day of post-fever isolation is optimal, 
118 and the model could help determine if additional days of isolation would be beneficial.

119 Additionally, we hypothesized that the short school-week policy, although disruptive, may be

120 more effective for both infections since it could be easier to enforce than symptom-based

121 isolation. In the case of COVID-19, the policy has the advantage of not being affected by the low

122 rate of symptomatic infections among children(Poletti et al., 2020).

123

124 Materials and Methods

125 We use a deterministic compartmental dynamical model known as the Susceptible, Exposed,

126 Infectious, Recovered (SEIR) model that tracks the number of individuals of various cohorts

127 immunological states, and degree of isolation for each day during an outbreak (Figure 1A, Table

128 1). This class of SEIR models has been used extensively to model influenza(Andreasen \&

129 Frommelt, 2005; Coburn, Wagner \& Blower, 2009; Modchang et al., 2012; Chen et al., 2019)

130 and COVID-19(Wang et al., 2020; He, Peng \& Sun, 2020), and we extended the SEIR

131 framework in order to account for isolation policies (Box 1).

TABLE 1 ABOUT HERE

133

BOX 1 ABOUT HERE

138 Our model is particularly novel as it further stratifies the population by both the day of their

139 infection, their location (isolated at home vs. not isolated in school) and their grade, with

140 students in the same grade generally having closer contacts to peers in the same grade(Glass \& 
141 Glass, 2008) (see Figure 1B, Supplemental Article S1 - Expanded Methods for details). In the

142 model, the day of infection determines the rate of virus shedding and the probability of

143 symptoms, which then influences the likelihood of either isolating at home or returning to

144 school. The probability of isolating was also based on the stage of the illness, as well as the

145 isolation policy. The model allowed a vaccine to be received by some students, if the vaccine is

146 available ahead of the outbreak, attaining partial protection against the infection. The model also

147 considered any pre-existing immunity, the rate of symptomatic infections, and school holidays.

148 Policy analysis used the setting of a typical school (6 grades with 70 students each)(“Common

149 Core of Data (CCD)"), but also considered alternative scenarios with larger schools (140

150 students per grade).

151

152 The model was validated on outbreaks of influenza and COVID-19 in schools and shown to

153 match the peak and duration of the outbreak curves, and the overall attack rates of the student

154 population. The validation data was from two outbreaks of pandemic influenza(Smith et al.,

155 2009),(Bhattarai et al., 2011), one outbreak of seasonal influenza(McCann et al., 2014), and one

156 outbreak of COVID-19(“3 teachers in shuttered Jerusalem school have virus; pupils, staff to be

157 tested"). Model parameter ranges were derived from published sources and by calibration to data

158 using a stochastic optimization algorithm.

159 The estimated parameters were: (a) the overall transmissibility of the virus, (b) the relative

160 transmissibility on weekends and (c) during school closures, (d) the effect of the season on

161 transmission, (e) parental attention to symptoms, and (f) compliance to the symptom isolation

162 policy (see Appendix, Table S2). The transmissibility (a) was calibrated separately for influenza 163 and COVID-19. 
165 To ensure that the results were robust to uncertainty in parameter values, we then simulated the

166 epidemic 500 times per scenario to account for possible difference between schools and seasons,

167 with normally distributed values for parameters such as the start day in the year, contact rate

168 between cohorts and others, and reported the median and the interquartile ranges. All modeling

169 and statistical analysis used the RStudio Integrated Development for R. RStudio, Inc., Boston,

170 MA. Further details on the model, including the equations and the parameter values, are provided

171 in Supplemental Article S1 - Expanded Methods. In addition to this text, we provide the source

172 code for the model, the associated data, and the expanded results

173 (https://github.com/sashagutfraind/feverfighter). A live configurable dashboard for applying the 174 model is also available (https://epil.shinyapps.io/FeverFighter/).

175

176

177 Using the model we considered the effect of two key control policies, fever-based isolation and a

178 shortened school week. For fever-based isolation we evaluated the effect of stricter compliance,

179 which could be attained by remote monitoring, help in maintaining home isolation or penalties

180 for non-compliance. We also considered the effect of increasing the monitoring of symptoms,

181 which could be attained through training of the parents and distribution of free thermometers.

182 We also considered supplemental policies: subdividing students into cohorts of half the normal

183 size, reducing contacts between cohorts, and enforcing strict quarantines on weekends. We

184 evaluated all policies using three outcome measures: (1) the attack rate - the proportion of the

185 population infected during the outbreak, (2) the outbreak duration - the number of days with 
186 more than one infected student, and also (3) the peak number of simultaneously infected - a

187 measure of the burden on the caregivers and the healthcare system.

188

\section{Results}

190 Our analysis considered the effect of symptom-based isolation and alternative school schedule

191 policies on influenza and SARS-CoV-2 infections. The effect of these policies is summarized in

192 Table 2 and described in detail below.

TABLE 2 ABOUT HERE

194

195

\section{Influenza}

196 We calibrated our model's parameters to outbreaks of pandemic and seasonal influenza and then

197 calculated each isolation policy 500 times. ${ }^{1}$ The different runs varied parameters that normally

198 vary from year to year (e.g. outbreak start day and compliance with policy). In the baseline

199 scenario of pandemic influenza and no isolation policy, our model has a median attack rate of

20024.5 (Interquartile Range, IQR: 16.6 - 28.1)\%. Implementing a one- and two-day isolation policy

201 following fever, our model predicts a decrease in the attack rate to $17.2(9.9-21.4) \%$ and 7.4

$202(3.7-11.1) \%$, respectively (Figure 2).

\footnotetext{
${ }^{1}$ In the simulations, the input parameters were chosen at random but symmetrically around the calibrated values. However, the effect of deviations from the calibrated values is asymmetrical on the outbreak, causing the median value of measures like the attack rate in the 500 simulations to differ from the baseline value $(25 \%$ attack rate for influenza and 11.3\% attack rate for SARS-CoV-2). Reducing the magnitudes of the deviations removes this effect.
} 
204 Furthermore, the model predicts that a two-day isolation policy reduces the peak prevalence (i.e.

205 simultaneously infected students) from $20(13-25)$ to $5(2-8)$ and the outbreak duration from

$20682(78-84)$ to $67(28-77)$ days. Our model suggests that the two-day policy is still effective

207 even when the student population has pre-existing immunity or has been vaccinated (mean

208 vaccination rate of $80 \%$ and efficacy of $50 \%)$, reducing the attack rate to $13(4.2-23.8) \%{ }^{2}$.

209 We have also examined the policy of reducing the number of days of in-person study. A policy

210 of a four-day school week gives a 73\% reduction in the attack rate from the baseline, to 6.8 (3.3 -

$2118.8) \%$, and a three-day school week gives a 93\% reduction to $1.8(0.9-2.3)$ (Figure 2B). The

212 two-day of post-fever isolation and three-day week policies could be combined additively with

213 two days of post-fever isolation to give attack rates of $2.1(1.0-3.3) \%$ and $0.9(0.5-1.2) \%$,

214 respectively.

215

216

217

218

219

220

221

222

223

\section{COVID-19 (SARS-CoV-2)}

\section{FIGURE 3 ABOUT HERE}

In our COVID-19 outbreak scenarios, in the absence of policy measures, the baseline attack rate was $10.0(8.7-11.3) \%$ in 500 simulations. As expected based on the lower rate of symptomatic infections in COVID-19 as compared to influenza, post-fever isolation policy is less effective for COVID-19: 1, 2, and 14 days of isolation yielded attacks rates of $9.4(8.3-10.6) \%, 9.2(8.0$ 10.6)\%, and 8.5 (7.4 - 9.7)\%, respectively (Figure 3, A). Additionally, our model had a baseline outbreak duration of 138 (135 - 140) days and yielded outbreak durations of 137 (133 - 139), 136 (132 - 139), and 132 (128 - 134) days for 1,2, and 14 days of post-fever isolation. Thus when

\footnotetext{
2 The policy appears to be less effective in the presence of immunity due to a paradoxical effect noted in Ref (Echevarria et al., 2015). In both the no immunity and immunity scenarios we assume an attack rate of $25 \%$, but in the presence of immunity, the virus needs to have higher transmissibility to achieve this attack rate and is thus harder to control.
} 
224 compared to the influenza outbreaks, this type of policy was less effective at attack rate or 225 outbreak duration inhibition.

226 Evaluating the policy of shortening the school week, our model found that using four and three 227 days of in-person schooling yields attack rates of $4.4(3.7-4.9) \%$ and $2.0(1.7-2.2) \%$,

228 respectively (Figure 3, B). When the student population is presumed to be immune(Sette \& 229 Crotty, 2020) or vaccinated at a rate of $80 \%$ and with an efficacy of $70 \%$ (Standard Deviation, 230 SD: 20\%), the model predicts that the policy is still effective: for the 4- and 3-day school week, 231 the model predicts a median attack rate of $5.1(1.8-15.2) \%$ and $2.7(1-6.6) \%$, respectively.

232 For both influenza and COVID-19, we examined additional policy options to complement the 233 two main policies of post-fever isolation and shortening the school week. In the case of 234 symptom-based isolation for influenza, measures that increase compliance and symptom 235 monitoring were found to be effective: a $25 \%$ increase in attention and compliance reduces the 236 attack rate to $3.4(1.5-5.2) \%$ and $7.3(3.5-11.2) \%$, respectively. For both infections, reducing 237 contacts between student grades within a school was found to be very effective and could be 238 complementary to the main policies. Implementing strict quarantines on weekends were also 239 found to be effective.

\section{Discussion}

242 Outbreaks of acute respiratory infections such as influenza and the novel COVID-19 require an 243 expansion of the available infection control policies. Here we report evidence in support of

244 several such policies across outbreak scenarios and settings. For influenza, requiring isolation for 245 fever is expected to reduce the typical attack rate by $29(13-59) \%$ and $70(55-85) \%$ with one 
246 and two days of post-fever isolation, respectively. This indicates that the CDC-recommended

247 policy for schools, based on a single day of post-fever isolation, could be enhanced by requiring

248 a second day of isolation. The result also holds in seasonal influenza in which vaccination is

249 implemented. The isolation policy could be further strengthened by reducing contact between

250 students during weekends. Using a shorter in-person school week (i.e., through longer weekends

251 or remote learning) would also reduce the attack rate by $73(64-88) \%$ and $93(91-97) \%$ with

252 four and three-day school weeks, respectively. The high percentage of reduction arises because

253 these measures are expected to bring the epidemic under the outbreak threshold, and assumes no

254 re-introduction of the infection from outside the school.

255

256 While we expected symptom-based isolation to be ineffective for COVID-19 since children are

257 commonly asymptomatic(He et al.), it can still help in reducing outbreaks. Many authorities,

258 including the $\mathrm{CDC}$ and $\mathrm{WHO}$, recommend that those with symptoms isolate for a minimum of

25910 days after symptom onset(WHO),(Centers for Disease Control and Prevention, 2020).

260 Indeed, we found that a one-day post-fever isolation policy would reduce the attack rate in

261 schools by $7(5-14) \%$, and with 14 days of fever isolation we estimated that the attack rate

262 would change by $14(5-26) \%$. The result shows that symptom-based isolation cannot be relied

263 upon as a central policy in outbreak control for COVID-19, but it is not futile. Current CDC and

264 WHO isolation policies for COVID-19 are expected to have effectiveness between the one-day

265 and 14-day fever-based isolation policies above, but require only one day of isolation following

266 any fever (CDC) and three days of isolation following cessation of symptoms (WHO). We found

267 that shortening the school week does reduce the total number infected in an outbreak by 57 (52 -

$26864) \%$ and $81(79-83) \%$, with four and three days of in-person schooling, respectively. 
270 There are several possibilities for how shortening of the school week may reduce the

271 transmission. It could: (1) reduce the amount of time the infected and uninfected populations

272 mix, or (2) create an extended period of isolation of the infectees. To identify the cause, we held

273 (1) constant by using a policy of 4 days of schooling per week but varied (2). Namely, we

274 performed simulations where an outbreak was controlled using three different regimens with a

275 shortened school week: (a) a regimen where over a two week period, the school is closed on days

276 4, 6, 8, 10, 12, and 14, (b) closing for three days every Friday (i.e., closures on days 5, 6, 7, 12,

277 13, and 14), and a school that opens for eight days and closes for six days straight. The attack

278 rate was lowest in the third policy: for influenza, the regimens produced attack rates of $6.8 \%$,

$2795.3 \%$ and 3.8, and for SARS-CoV-2: 4.6\%, 4.7\%, and 3.7\%. We conclude that the short school

280 week acts both to reduce the amount of mixing and separately by creating a continuous period of 281 isolation.

282

283 Generally speaking, policies that isolate the infected, of which symptom-based isolation is a sub284 type, are more preferable to closures. Unlike closures, symptom-based isolation allows healthy 285 people in the community to continue living their lives uninhibited and reduces the considerable 286 societal cost of school closures(Viner et al., 2020). Consequently, a standing policy of isolation 287 of infected individuals could potentially be sustained indefinitely. Shorter school weeks do affect 288 all students, but they are less disruptive than full closures. They can also be maintained for 289 extended times during the peak of the outbreak season, particularly if school days are replaced 290 with remote learning (self study or e-learning). In severe outbreaks, a combination of policies

291 would provide the best outcomes. High compliance by families would be critical to ensuring that 
292 the students are strongly isolated when the school is closed, and therefore families need to be 293 supported.

294

295 While our model is driven by virological data and calibrated to several outbreaks, a few

296 limitations are inherent in our approach. First, the effect of any policy depends on the context

297 where it would be applied. The details of the school or institution would matter, and therefore, 298 we provide an online version of the model, which can be calibrated for multiple situations. Better 299 calibration data would help improve the calibration of the model, and in certain datasets it was 300 not established if the absence was due to the outbreak or due to other causes. It may be possible 301 to apply our findings to school-like contexts such as workplaces, prisons, or even the broader 302 community, but such settings have significant features that may confound our findings. Lastly, 303 symptom parameter information is based on average values for the population and it is expected

304 that inter-individual and demographic variability might have some effect on outcomes. Future 305 studies should attempt to evaluate isolation policies with agent-based models (e.g. (Chao et al., 306 2010; Gutfraind et al., 2015)) that can capture inter-individual variability in health trajectories 307 and the network structure of the population(Lloyd-Smith et al., 2005; Volz et al., 2011). Despite 308 these limitations, our model captures essential aspects of acute respiratory outbreaks including 309 progression through stages, the population structure and symptom trajectories.

311 In conclusion, in this study we have created a model of transmission of respiratory infection and

312 considered the effects of two isolation policies. We confirmed that symptom-based policies

313 would be effective in controlling influenza in a variety of scenarios. Furthermore for influenza

314 outbreaks, we recommend that isolation is maintained for at least two days following the last day 
315 of fever. For both influenza and COVID-19 we found that using a shortened school-week of

316 four days instead of five days could be effective in reducing the attack rate, and additional days

317 would increase the effect. Policymakers tackling the influenza and COVID-19 outbreaks should

318 consider implementing these policies for controlling outbreaks in schools and other settings.

319

320 Supplementary Data

321 Supplemental Digital Content is available online and include the model source code, an

322 interactive online dashboard, and additional simulation data.

323

324 Notes

325 Financial support. The US National Institute of Allergy and Infectious Diseases provided 326 funding through a grant to AG (R01GM121600).

327 Acknowledgements. Mark Dworkin, MD consulted on school absenteeism policies, and the

328 following people provided comments: Alisa Ungar-Sargon, Michael Genkin, Michael Z. Levy,

329 Edward A. Belongia, Sami Alhamdi, and Mitch Croal.

330 Potential conflicts of interest. All authors: No reported conflicts.

331

332

333 


\section{REFERENCES}

3353 teachers in shuttered Jerusalem school have virus; pupils, staff to be tested. Available at

336 https://www.timesofisrael.com/3-teachers-in-shuttered-jerusalem-school-have-virus-pupils-

337 staff-to-be-tested/(accessed July 19, 2020).

338 Andreasen V, Frommelt T. 2005. A School-Oriented, Age-Structured Epidemic Model. SIAM

339 journal on applied mathematics 65:1870-1887.

340 Araz OM, Damien P, Paltiel DA, Burke S, van de Geijn B, Galvani A, Meyers LA. 2012.

341 Simulating school closure policies for cost effective pandemic decision making. BMC

$342 \quad$ public health 12:449.

343 Bansal S, Pourbohloul B, Hupert N, Grenfell B, Meyers LA. 2010. The shifting demographic

$344 \quad$ landscape of pandemic influenza. PloS one 5:e9360.

345 Bhattarai A, Villanueva J, Palekar RS, Fagan R, Sessions W, Winter J, Berman L, Lute J, Leap

346 R, Marchbanks T, Sodha SV, Moll M, Xu X, Fry A, Fiore A, Ostroff S, L. Swerdlow D.

347 2011. Viral Shedding Duration of Pandemic Influenza A H1N1 Virus during an Elementary

348 School Outbreak-Pennsylvania, May-June 2009. Clinical infectious diseases: an official

$349 \quad$ publication of the Infectious Diseases Society of America 52:S102-S108.

350 Brauner JM, Mindermann S, Sharma M, Johnston D, Salvatier J, Gavenčiak T, Stephenson AB,

351 Leech G, Altman G, Mikulik V, Norman AJ, Monrad JT, Besiroglu T, Ge H, Hartwick MA,

352 Teh YW, Chindelevitch L, Gal Y, Kulveit J. 2020. Inferring the effectiveness of

353 government interventions against COVID-19. Science. DOI: 10.1126/science.abd9338.

354 Carrat F, Vergu E, Ferguson NM, Lemaitre M, Cauchemez S, Leach S, Valleron A-J. 2008.

355 Time lines of infection and disease in human influenza: a review of volunteer challenge

356 studies. American journal of epidemiology 167:775-785. 
357 Cauchemez S, Ferguson NM, Wachtel C, Tegnell A, Saour G, Duncan B, Nicoll A. 2009.

358 Closure of schools during an influenza pandemic. The Lancet infectious diseases 9:473359481.

360 Centers for Disease Control and Prevention. 2018. Guidance for School Administrators to Help

$361 \quad$ Reduce the Spread of Seasonal Influenza in K-12 Schools $\mid$ CDC.

362 Centers for Disease Control and Prevention. 2020. When You Can be Around Others After You

363 Had or Likely Had COVID-19. Available at https://www.cdc.gov/coronavirus/2019-ncov/if-

364 you-are-sick/end-home-isolation.html (accessed October 11, 2020).

365 Chao DL, Halloran ME, Obenchain VJ, Longini IM Jr. 2010. FluTE, a publicly available

366 stochastic influenza epidemic simulation model. PLoS computational biology 6:e1000656.

367 Chen S-I, Wu C-Y, Wu Y-H, Hsieh M-W. 2019. Optimizing influenza vaccine policies for 368 controlling 2009-like pandemics and regular outbreaks. PeerJ 7:e6340.

369 Christensen C, Albert I, Grenfell B, Albert R. 2010. Disease Dynamics in a Dynamic Social $370 \quad$ Network. Physica A 389:2663-2674.

371 Coburn BJ, Wagner BG, Blower S. 2009. Modeling influenza epidemics and pandemics: insights 372 into the future of swine flu (H1N1). BMC medicine 7:30.

373 Common Core of Data (CCD).

374 Cowling BJ, Ali ST, Ng TWY, Tsang TK, Li JCM, Fong MW, Liao Q, Kwan MYW, Lee SL,

375 Chiu SS, Wu JT, Wu P, Leung GM. 2020. Impact assessment of non-pharmaceutical

376 interventions against COVID-19 and influenza in Hong Kong: an observational study.

$377 \quad$ Epidemiology.

378 Diedrichs DR, Isihara PA, Buursma DD. 2014. The schedule effect: can recurrent peak

379 infections be reduced without vaccines, quarantines or school closings? Mathematical 
biosciences 248:46-53.

381 Eames KTD. 2014. The influence of school holiday timing on epidemic impact. Epidemiology

$382 \quad$ and infection 142:1963-1971.

383 Echevarria D, Gutfraind A, Boodram B, Major M, Del Valle S, Cotler SJ, Dahari H. 2015.

384 Mathematical Modeling of Hepatitis C Prevalence Reduction with Antiviral Treatment

385 Scale-Up in Persons Who Inject Drugs in Metropolitan Chicago. PloS one 10:e0135901.

386 Faherty LJ, Schwartz HL, Ahmed F, Zheteyeva Y, Uzicanin A, Uscher-Pines L. 2019. School

387 and preparedness officials' perspectives on social distancing practices to reduce influenza

388 transmission during a pandemic: Considerations to guide future work. Preventive medicine

389 reports $14: 100871$.

390 Ferguson NM, Cummings DAT, Fraser C, Cajka JC, Cooley PC, Burke DS. 2006. Strategies for

391 mitigating an influenza pandemic. Nature 442:448-452.

392 Glass LM, Glass RJ. 2008. Social contact networks for the spread of pandemic influenza in

393 children and teenagers. BMC public health 8:61.

394 Gutfraind A, Boodram B, Prachand N, Hailegiorgis A, Dahari H, Major ME. 2015. Agent-Based

395 Model Forecasts Aging of the Population of People Who Inject Drugs in Metropolitan

396 Chicago and Changing Prevalence of Hepatitis C Infections. PloS one 10:e0137993.

397 Halloran ME, Ferguson NM, Eubank S, Longini IM Jr, Cummings DAT, Lewis B, Xu S, Fraser

398 C, Vullikanti A, Germann TC, Wagener D, Beckman R, Kadau K, Barrett C, Macken CA,

399 Burke DS, Cooley P. 2008. Modeling targeted layered containment of an influenza

400 pandemic in the United States. Proceedings of the National Academy of Sciences of the

$401 \quad$ United States of America 105:4639-4644.

402 He X, Lau EHY, Wu P, Deng X, Wang J, Hao X, Lau YC, Wong JY, Guan Y, Tan X, Mo X, 
403

404

405

406

407

408

409

410

411

412

413

414

415

416

417

418

419

420

421

422

423

424

425

Chen Y, Liao B, Chen W, Hu F, Zhang Q, Zhong M, Wu Y, Zhao L, Zhang F, Cowling BJ, Li F, Leung GM. Temporal dynamics in viral shedding and transmissibility of COVID-19. Nature Medicine 26:672-675.

He S, Peng Y, Sun K. 2020. SEIR modeling of the COVID-19 and its dynamics. Nonlinear dynamics:1-14.

Information till förskola, grundskola och gymnasier om covid-19 — Folkhälsomyndigheten. Available at http://www.folkhalsomyndigheten.se/smittskydd-beredskap/utbrott/aktuellautbrott/covid-19/verksamheter/information-till-skola-och-forskola-om-den-nya-sjukdomencovid-19/ (accessed June 28, 2020).

Jackson C, Vynnycky E, Hawker J, Olowokure B, Mangtani P. 2013. School closures and influenza: systematic review of epidemiological studies. BMJ open 3. DOI: 10.1136/bmjopen-2012-002149.

Karin O, Bar-On YM, Milo T, Katzir I, Mayo A, Korem Y, Dudovich B, Yashiv E, Zehavi AJ, Davidovich N, Milo R, Alon U. 2020. Adaptive cyclic exit strategies from lockdown to suppress COVID-19 and allow economic activity. Epidemiology.

Kelso JK, Milne GJ, Kelly H. 2009. Simulation suggests that rapid activation of social distancing can arrest epidemic development due to a novel strain of influenza. BMC public health $9: 117$

Lee BY, Brown ST, Cooley P, Potter MA, Wheaton WD, Voorhees RE, Stebbins S, Grefenstette JJ, Zimmer SM, Zimmerman RK, Assi T-M, Bailey RR, Wagener DK, Burke DS. 2010. Simulating school closure strategies to mitigate an influenza epidemic. Journal of public health management and practice: JPHMP 16:252-261.

Lloyd-Smith JO, Schreiber SJ, Kopp PE, Getz WM. 2005. Superspreading and the effect of 
individual variation on disease emergence. Nature 438:355-359. DOI:

427 10.1038/nature04153.

Mathers C, World Health Organization. 2008. The Global Burden of Disease: 2004 Update.

$429 \quad$ World Health Organization.

McCann LJ, Suchanek O, McCarthy ND, Mannes T. 2014. Descriptive epidemiology of school outbreaks of seasonal influenza B during 2012/2013 in the Thames Valley, United Kingdom. Public health 128:1121-1124.

Miller JR, Short VL, Wu HM, Waller K, Mead P, Kahn E, Bahn BA, Dale JW, Nasrullah M, Walton SE, Urdaneta V, Ostroff S, Averhoff F. 2013. Use of nonpharmaceutical interventions to reduce transmission of 2009 pandemic influenza A (pH1N1) in Pennsylvania public schools. The Journal of school health 83:281-289. the transmission of infectious diseases: comparison of school closure as an intervention in

Modchang C, Iamsirithaworn S, Auewarakul P, Triampo W. 2012. A modeling study of school closure to reduce influenza transmission: A case study of an influenza A (H1N1) outbreak in a private Thai school. Mathematical and computer modelling 55:1021-1033.

Peak CM, Childs LM, Grad YH, Buckee CO. 2017. Comparing nonpharmaceutical interventions for containing emerging epidemics. Proceedings of the National Academy of Sciences of the

Poletti P, Tirani M, Cereda D, Trentini F, Guzzetta G, Sabatino G, Marziano V, Castrofino A, Grosso F, Castillo GD, Piccarreta R, Force ALC-19 T, Andreassi A, Melegaro A, Gramegna M, Ajelli M, Merler S. 2020. Probability of symptoms and critical disease after 
SARS-CoV-2 infection. arXiv [q-bio.PE].

450 Qualls N, Levitt A, Kanade N, Wright-Jegede N, Dopson S, Biggerstaff M, Reed C, Uzicanin A, 451 CDC Community Mitigation Guidelines Work Group. 2017. Community Mitigation

452 Guidelines to Prevent Pandemic Influenza - United States, 2017. $M M W R$.

453 Recommendations and reports: Morbidity and mortality weekly report. Recommendations 454 and reports / Centers for Disease Control 66:1-34.

455 Rhodes CJ, Hollingsworth TD. 2009. Variational data assimilation with epidemic models. Journal of theoretical biology 258:591-602.

457

458

460

461

462

463

464

465

466

467

468

469

470

471

Sasaki A, Hoen AG, Ozonoff A, Suzuki H, Tanabe N, Seki N, Saito R, Brownstein JS. 2009. Evidence-based Tool for Triggering School Closures during Influenza Outbreaks, Japan. Emerging infectious diseases 15:1841-1843.

Sette A, Crotty S. 2020. Author Correction: Pre-existing immunity to SARS-CoV-2: the knowns and unknowns. Nature reviews. Immunology 20:644.

Smith A, Coles S, Johnson S, Saldana L, Ihekweazu C, O’Moore É. 2009. An outbreak of influenza A(H1N1)v in a boarding school in South East England, May-June 2009. Eurosurveillance 14. DOI: 10.2807/ese.14.27.19263-en.

Stebbins S, Cummings DAT, Stark JH, Vukotich C, Mitruka K, Thompson W, Rinaldo C, Roth L, Wagner M, Wisniewski SR, Dato V, Eng H, Burke DS. 2011. Reduction in the incidence of influenza A but not influenza B associated with use of hand sanitizer and cough hygiene in schools: a randomized controlled trial. The Pediatric infectious disease journal 30:921926.

Viner RM, Russell SJ, Croker H, Packer J, Ward J, Stansfield C, Mytton O, Bonell C, Booy R. 2020. School closure and management practices during coronavirus outbreaks including 
COVID-19: a rapid systematic review. The Lancet Child \& Adolescent Health 4:397-404.

473 Volz EM, Miller JC, Galvani A, Ancel Meyers L. 2011. Effects of heterogeneous and clustered 474 contact patterns on infectious disease dynamics. PLoS computational biology 7:e1002042.

475 Wang H, Wang Z, Dong Y, Chang R, Xu C, Yu X, Zhang S, Tsamlag L, Shang M, Huang J, 476 Wang Y, Xu G, Shen T, Zhang X, Cai Y. 2020. Phase-adjusted estimation of the number of 477 Coronavirus Disease 2019 cases in Wuhan, China. Cell discovery 6:10.

478 WHO.Criteria for releasing COVID-19 patients from isolation. Available at 479 https://www.who.int/news-room/commentaries/detail/criteria-for-releasing-covid-19480 patients-from-isolation (accessed September 29, 2020).

481 WHO | Non-pharmaceutical public health measures for mitigating the risk and impact of $482 \quad$ epidemic and pandemic influenza. 2019. 


\section{Figure 1}

The model

(A) Dynamics of the outbreak model and its major variables. $\mathrm{S}$, susceptible; $\mathrm{H}$, infected isolated; I, infected unisolated; R, recovered; and V, vaccinated or immune (if a vaccine is available). The students are stratified to cohorts, and $n$ daily disease stages distinguished by severity of symptoms and viral shedding ( 9 daily stages of viral shedding for influenza and 32 stages for COVID-19, see Supplemental Digital Content - Expanded Methods). The cohort structure and other parameters are adjustable to model outbreaks in different settings and by different pathogens. Vaccination is available only for some outbreaks and generally has incomplete coverage and efficacy. (B) Illustration of the typical connectivity pattern between cohorts in the school where the thickness of the arrows illustrates the greater risk of transmission within cohort than across cohorts (shown is the case of four cohorts).

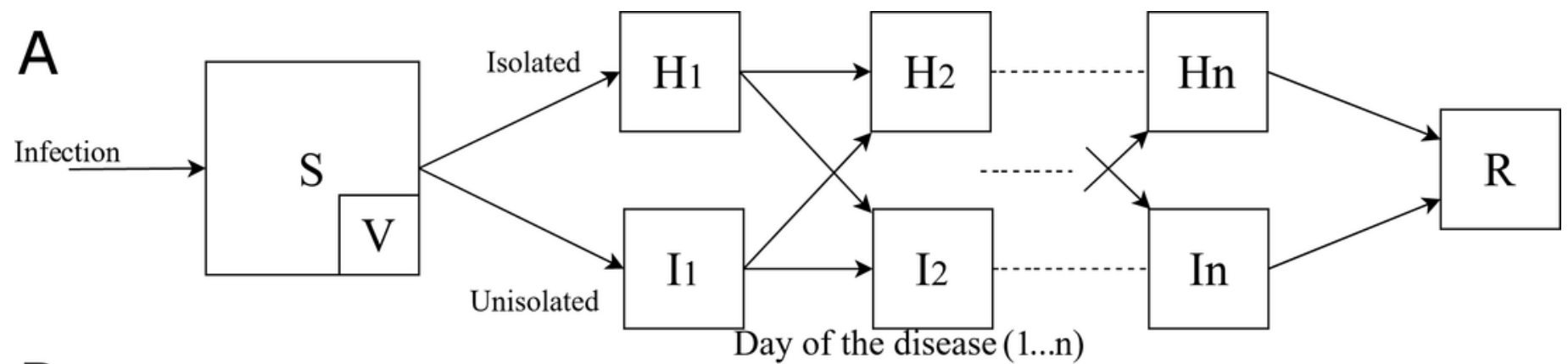

B

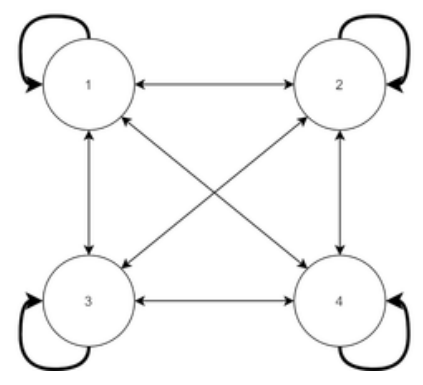




\section{Figure 2}

The effect of requiring isolation after the last fever event in a median US school experiencing an outbreak of influenza

(A) fever isolation and (B) shortened in-person school week. Vertical axis indicates daily prevalence and ripples are due to weekends and closures. Summer holiday starts June 17 and reduces transmission. Increasing the required days of isolation or shortening the inperson school week reduces the peak infected and the number concurrently infected. Only shortening the in-person school week reduces the duration of the outbreak. 


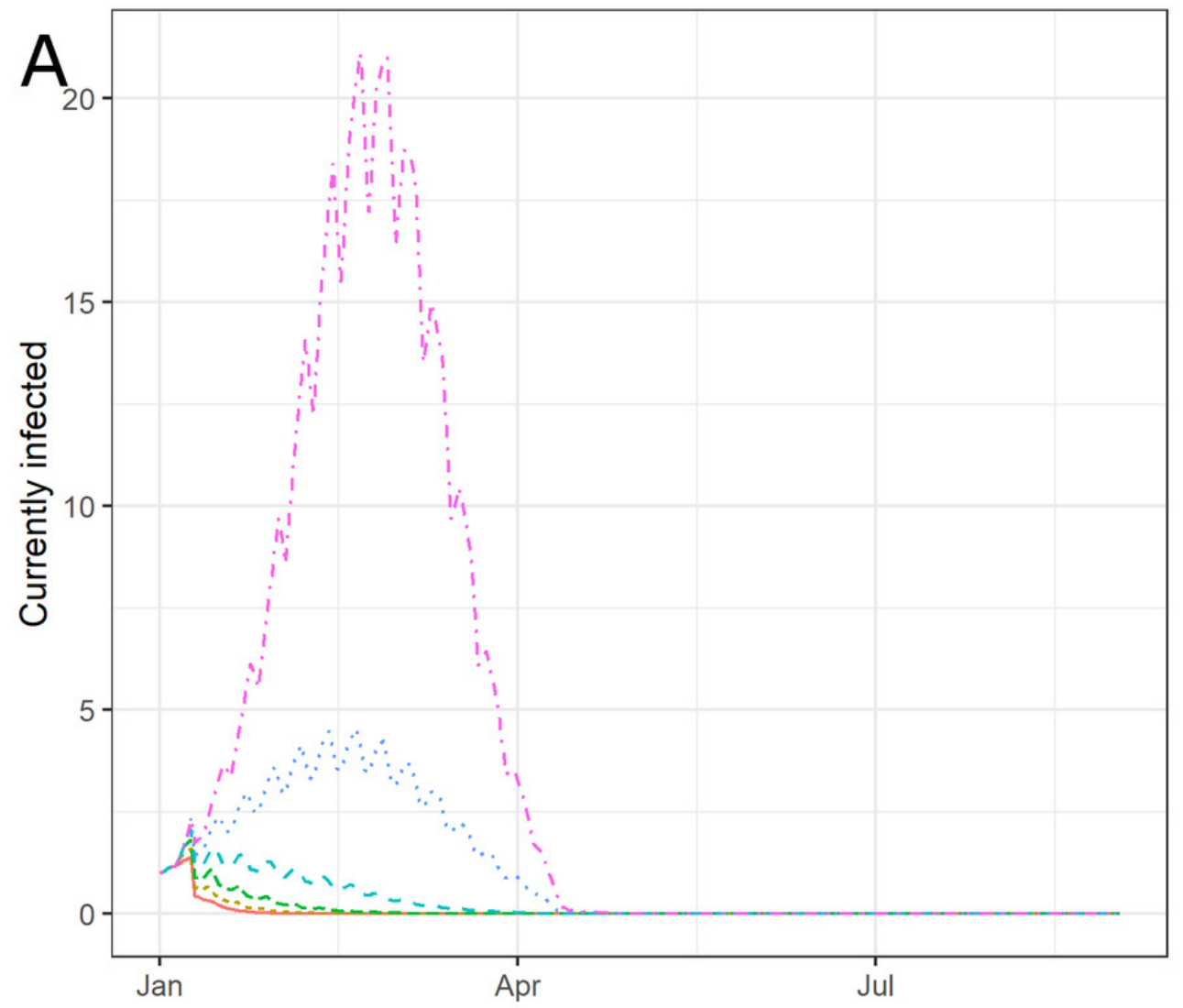

Weekly

days open

$-0$

-... 1

$---2$

$--3$

‥ 4

-. 5

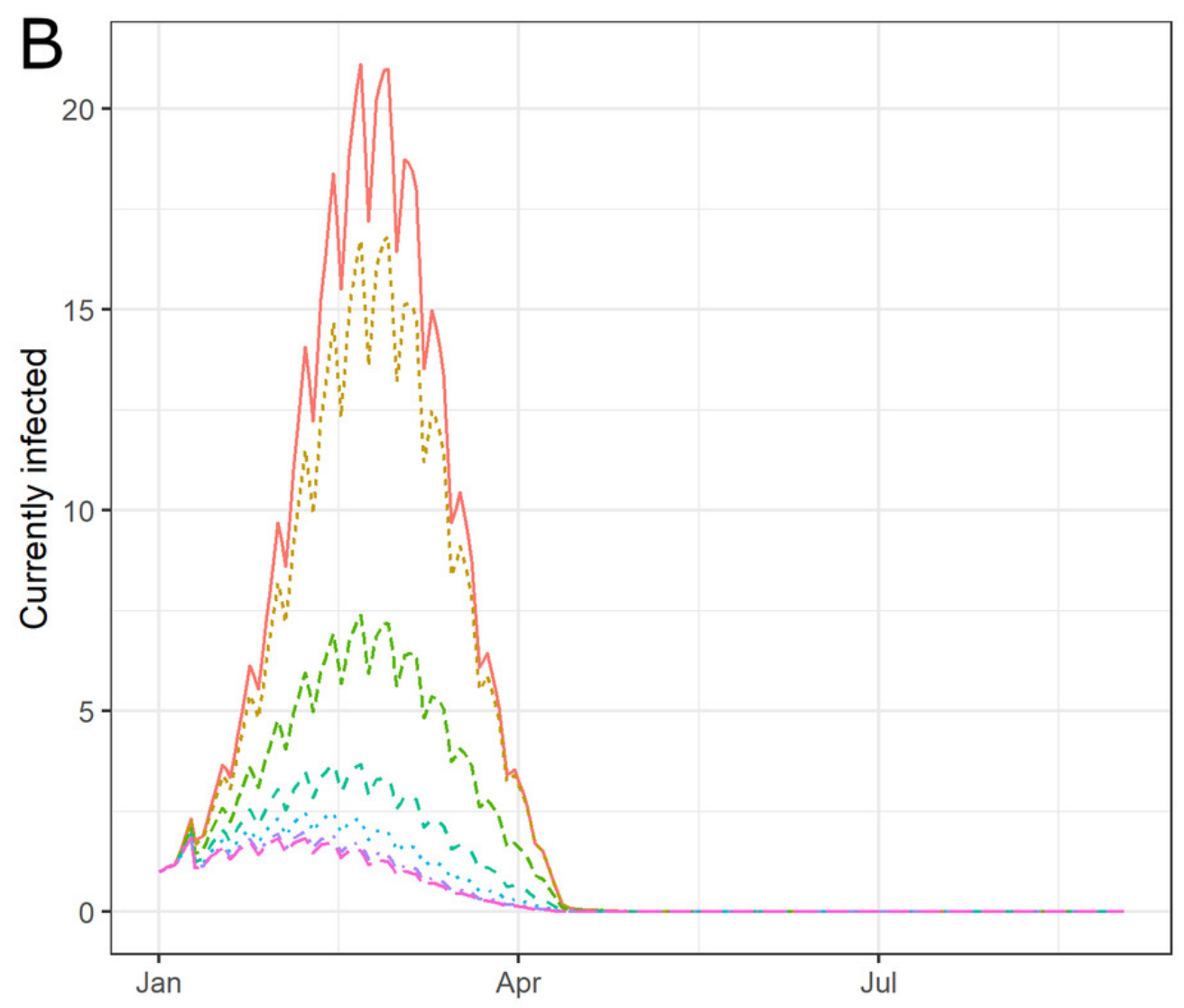

Required isolation days

$---2$

$--3$

… 4

-. 5

$--6$ 


\section{Box 1(on next page)}

Our modeling framework - the multi-state discrete time SEIR infection model stratified by cohort and day of infection 
1 Box 1. Our modeling framework - the multi-state discrete time SEIR infection model stratified

2 by cohort and day of infection. Cohorts normally correspond to student grades but they could

3 also include part of each grade and school staff. Variables are defined in Table 1 and are

4 dependent on time $t$. Index i runs over all cohorts in the school and index $\mathrm{d} \in\left\{1 \ldots \mathrm{d}_{\mathrm{f}}\right\}$ over the

5 days from day 1 after infection to recovery. Return rates from isolation at day $r_{d}(p)$ depend on

6 symptom isolation policy $\mathrm{p}, \delta_{1, \mathrm{~d}}$ is the Kronecker delta function ( $=1$ if $\mathrm{d}$ is 1 , and otherwise zero).

$7 \quad c_{i, j}$ is the connectivity between cohorts $i$ and jand $s_{d}$ is the viral shedding at day d of infection.

8 Estimates for the parameters are in Appendix Tables S2, S3 and S4.

$9 \Delta \mathrm{S}_{\mathrm{i}}=-\mathrm{bS}_{\mathrm{i}} \lambda_{\mathrm{i}}$, where $\lambda_{\mathrm{i}}=\sum_{j, d} c_{i, j} s_{d} I_{j, d}$ is the force of infection

$$
\begin{gathered}
10 \quad \mathrm{I}_{\mathrm{i}, \mathrm{d}}=\mathrm{r}_{\mathrm{d}}(\mathrm{p})\left(\mathrm{H}_{\mathrm{i}, \mathrm{d}-1}+\mathrm{I}_{\mathrm{i}, \mathrm{d}-1}\right)\left(1-\delta_{1, \mathrm{~d}}\right)+\delta_{1, \mathrm{~d}} \mathrm{bS}_{\mathrm{i}} \lambda_{\mathrm{i}} \\
\Delta \mathrm{R}_{\mathrm{i}}=\mathrm{H}_{\mathrm{i}, \mathrm{d}_{\mathrm{f}}}+\mathrm{I}_{\mathrm{i}, \mathrm{d}_{\mathrm{f}}}
\end{gathered}
$$




\section{Figure 3}

The effect of requiring isolation after the last fever event in a median US school experiencing an outbreak of COVID-19

(A) post-fever isolation and (B) in-person school-week reduction policies on a median US school experiencing an outbreak of COVID-19. Vertical axis indicates daily prevalence as in Fig 2. Increasing the number of post-fever isolation days has little effect on the outbreak. Reducing the number of school days that students physically go to school each week reduces the peak number of infected, the number concurrently infected, and the duration of the outbreak. 

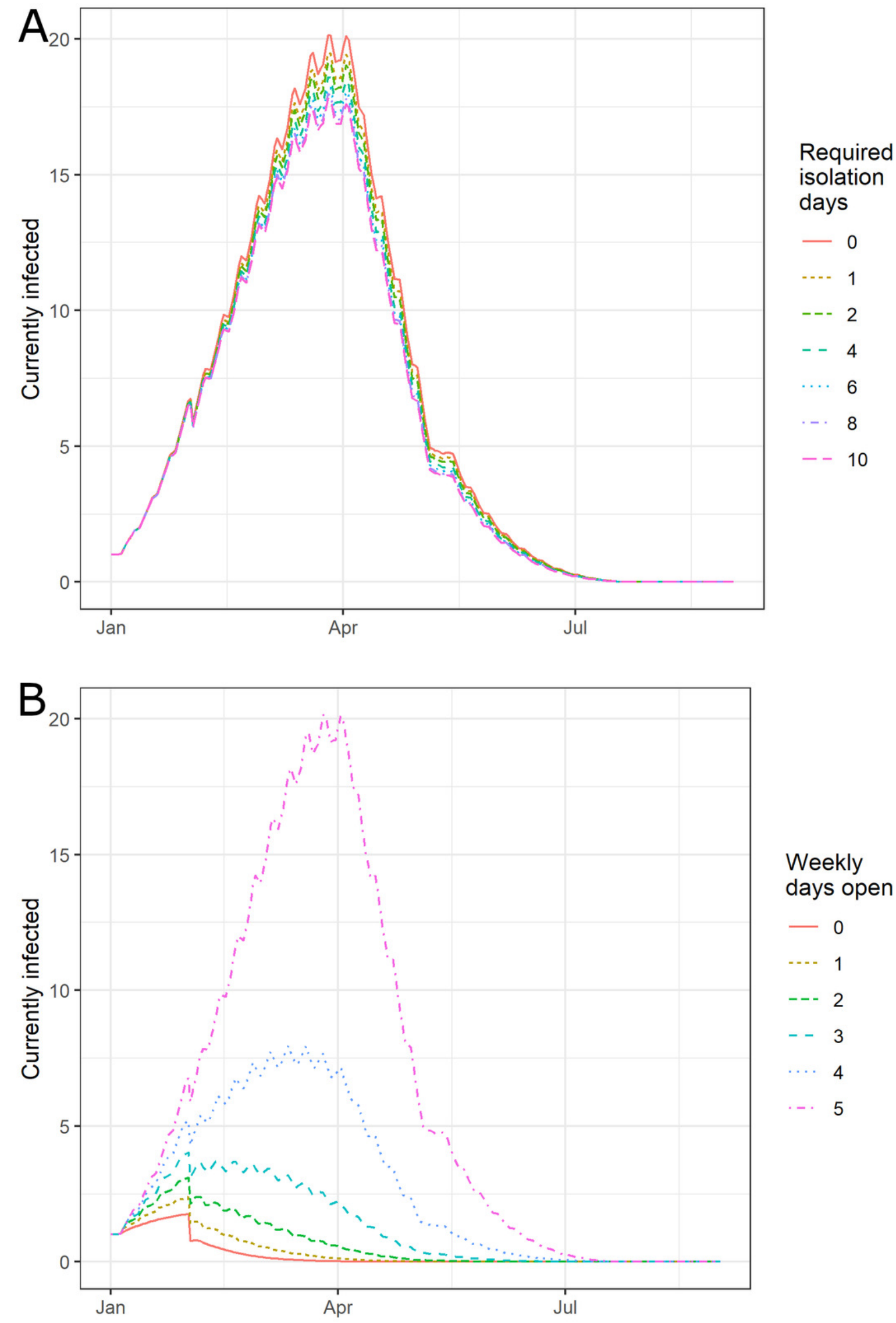

Weekly days open

- 0

-... 1

--- 2

$--3$

… 4

-. 5 


\section{Table $\mathbf{1}$ (on next page)}

Variables of the model

Index i indicates the cohort (normally student grade) and d the day of infection (running from 1 to 9 , or 32 for influenza and COVID-19, respectively) 
1 Table 1. Variables of the model. Index i indicates the cohort (normally student grade) and d the 2 day of infection (running from 1 to 9, or 32 for influenza and COVID-19, respectively)

\begin{tabular}{|l|l|}
\hline Variable & Interpretation \\
\hline$S_{i}$ & $\begin{array}{l}\text { Naïve persons in cohort } i \text { (for immunity, } \tilde{\mathrm{S}}_{\mathrm{i}}(0)=\mathrm{S}_{\mathrm{i}}(0)\left(1-\mathrm{vv}_{\mathrm{e}}\right), \text { where } \mathrm{v} \\
\text { is the fraction vaccinated and } v_{e} \text { is the vaccine efficacy. }\end{array}$ \\
\hline$I_{i, d}$ & Infected persons in cohort $i$ on day $d$ of infection who are not isolated \\
\hline$H_{i, d}$ & Similarly, but who are $i$ solated (e.g. at home) \\
\hline$R_{i}$ & Recovered in cohort $i$ \\
\hline
\end{tabular}

3 
Table 2 (on next page)

Relative effectiveness of isolation policies

Median effect (interquartile range) 
1 Table 2. Relative effectiveness of isolation policies. Median effect (interquartile range)

\begin{tabular}{|c|c|c|c|c|c|}
\hline \multirow[b]{2}{*}{ Outbreak } & \multirow[b]{2}{*}{ Policy option } & \multicolumn{2}{|c|}{ Attack rate } & \multicolumn{2}{|c|}{ Outbreak duration } \\
\hline & & Baseline & $\%$ decrease & Baseline (days) & $\%$ decrease \\
\hline \multirow[t]{4}{*}{ Flu } & $\begin{array}{l}\text { One day } \\
\text { isolation } \\
\text { (CDC } \\
\text { guideline) }\end{array}$ & \multirow[t]{4}{*}{$25 \%$} & $29(13-59) \%$ & \multirow[t]{4}{*}{82} & $1(-2-16) \%$ \\
\hline & $\begin{array}{l}\text { Two day } \\
\text { post-fever } \\
\text { isolation }\end{array}$ & & $70(55-85) \%$ & & $18(6-66) \%$ \\
\hline & $\begin{array}{l}\text { Four day } \\
\text { school week }\end{array}$ & & $73(64-88) \%$ & & $20(11-55) \%$ \\
\hline & $\begin{array}{l}\text { Three day } \\
\text { school week }\end{array}$ & & $93(91-97) \%$ & & $99(82-100) \%$ \\
\hline \multirow[t]{5}{*}{ COVID-19 } & $\begin{array}{l}\text { One day } \\
\text { isolation }\end{array}$ & \multirow[t]{5}{*}{$11.3 \%$} & $7(5-14) \%$ & \multirow[t]{5}{*}{138} & $1(1-4) \%$ \\
\hline & $\begin{array}{l}\text { Two day } \\
\text { post-fever } \\
\text { isolation }\end{array}$ & & $10(5-17) \%$ & & $1(1-4) \%$ \\
\hline & $\begin{array}{l}14 \text { day post- } \\
\text { fever } \\
\text { isolation }\end{array}$ & & $14(5-26) \%$ & & $4(3-7) \%$ \\
\hline & $\begin{array}{l}\text { Four day } \\
\text { school week }\end{array}$ & & $57(52-64) \%$ & & $22(12-26) \%$ \\
\hline & $\begin{array}{l}\text { Three day } \\
\text { school week }\end{array}$ & & $81(79-83) \%$ & & $46(33-52)$ \\
\hline
\end{tabular}

2

3 